\title{
Giant cell tumors of the spine: has denosumab changed the treatment paradigm?
}

\author{
Tony Goldschlager, MBBS, PhD, FRACS, ${ }^{1,8,9}$ Nicolas Dea, MD, MSc, FRCSC, ${ }^{1}$ \\ Michael Boyd, MD, FRCSC, ${ }^{1}$ Jeremy Reynolds, MBChB, FRCS(T\&O), ${ }^{3}$ Shreyaskumar Patel, MD, ${ }^{4}$ \\ Laurence D. Rhines, MD, ${ }^{5}$ Ehud Mendel, MD, ${ }^{6}$ Marina Pacheco, MD, ${ }^{2}$ Edwin Ramos, MD, ${ }^{6}$ \\ Tobias A. Mattei, MD, ${ }^{7}$ and Charles G. Fisher, MD, MHSc, FRCSC ${ }^{1}$
}

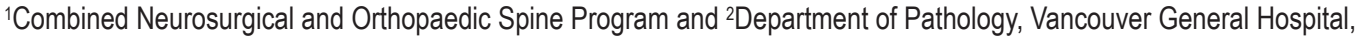
Vancouver, Canada; ${ }^{3}$ Spinal Unit, Oxford University Trust Hospital, Oxford, United Kingdom; Departments of ${ }^{4}$ Oncology and ${ }^{5}$ Neurosurgery, MD Anderson Cancer Center, Houston, Texas; Departments of 6 Neurosurgery and ${ }^{7}$ Oncology, Ohio State University, Columbus, Ohio; and ${ }^{8}$ Department of Neurosurgery, Monash Health, and ${ }^{9}$ Department of Surgery and Monash Institute of Medical Research, Monash University, Melbourne, Australia
\end{abstract}

\begin{abstract}
OBJECT Giant cell tumors (GCTs) of the spine are rare and complex to treat. They have a propensity for local recurrence and the potential to metastasize. Treatment is currently surgical and presents unique challenges due to the proximity of neural structures and the need for reconstruction. Denosumab has been shown in clinical trials to be an effective treatment for GCT, but has not yet been studied specifically in GCT of the spine or as a surgical adjunct. To the authors' knowledge this is the first such reported series.
\end{abstract}

METHODS A multicenter, prospective series of 5 patients with GCT of the spine treated with denosumab were included. Patient demographic data, oncological history, neurological status, tumor staging, treatment details and adverse events, surgical procedure, complications, radiological and histological responses, and patient outcome were analyzed.

RESULTS All patients were women, with a mean age of 38 years, and presented with pain; 2 patients had additional neurological signs and symptoms. The mean duration of symptoms was 62 weeks. No patient had a prior tumor or metastatic disease at presentation. All patients had Enneking Stage III tumors and were treated with monthly cycles of $120 \mathrm{mg}$ of denosumab, with initial additional loading doses on Days 8 and 15. Patients were given daily supplements of calcium $(500 \mathrm{mg})$ and vitamin D (400 lU). There were no denosumab-related adverse events. All patients had a radiological response to denosumab. One patient failed to have a histological response to denosumab, with $>90 \%$ of tumor cells found to be viable on histological investigation.

CONCLUSIONS This study reports the early experience of using denosumab in the treatment of spinal GCT. The results demonstrate a clinically beneficial radiological response and an impressive histological response in most but not all patients. Further experience with denosumab and longer patient follow-up is required. Denosumab has the potential to change the treatment paradigm for spinal GCT.

http://thejns.org/doi/abs/10.3171/2014.10.SPINE13937

KEY WORDS giant cell tumor; primary spine tumor; denosumab; en bloc resection; oncology

$\mathrm{G}$ IANT cell tumors (GCTs) typically occur in long bones and infrequently in the spine. Spinal GCT produces unique challenges for the spine surgeon because of the tumor's spectrum of clinical behavior and the complexities involved in resection. Pathologically they can range from active to aggressive, with the latter having a propensity for local recurrence and metastatic potential. Recognition of the aggressive tumors is critical because they require complex surgical treatment to minimize the chances of local recurrence..$^{2-4,11,15,17}$ Surgical en bloc re-

ABBREVIATIONS ASIA = American Spinal Injury Association; GCT = giant cell tumor; RANKL = receptor activator of nuclear factor kappa B ligand; WBB = WeinsteinBoriani-Biagini.

SUBMITTED October 22, 2013. ACCEPTED October 13, 2014.

INCLUDE WHEN CITING Published online February 20, 2015; DOI: 10.3171/2014.10.SPINE13937.

DISCLOSURE Dr. Rhines receives teaching honoraria from Stryker and Globus. Dr. Fisher is a consultant for Medtronic and NuVasive. Dr. Mendel receives a course faculty honorarium from Stryker. Dr. Goldschlager is a consultant for Mesoblast Limited. 
section of such primary bone lesions has been regarded as the gold standard treatment; ${ }^{13,20}$ however, surgery is typically marginal on the dural-tumor interface. ${ }^{11,16}$ Due to the tumor's proximity to the spinal cord and nerve roots as well as the need for intricate reconstruction, the associated morbidity and potential functional impairment are not trivial. ${ }^{19}$

Radiotherapy has been shown to produce tumor shrinkage and some improvement of neurological symptoms, ${ }^{14}$ however, the long-term control rate has been shown to be at best moderate (with only a 58\% disease-free survival rate at 5 years overall). Therefore, radiotherapy and radiosurgery are usually reserved for tumors that are not amenable to resection or for recurrent disease. ${ }^{6,14}$ Some other medical therapies have already been considered for the management of GCTs. Worthy of mentioning is the use of bisphosphonates, which have been shown to induce tumor regression in isolated case reports, ${ }^{1,10}$ and which have been demonstrated to significantly reduce the rates of local recurrence. ${ }^{12,21}$

Thus, curing GCT involves extensive decision making and weighing of probabilities. Having a treatment alternative or adjunct that requires less aggressive surgery would greatly facilitate this decision making and treatment process, especially with the complex regional anatomy of the spine.

Giant cell tumors are so named because they appear histologically as nodules of osteoclast-like giant cells, from which they arise. Osteoclasts express the receptor activator of nuclear factor kappa B ligand (RANKL), which is an essential mediator for osteoclast survival. Denosumab, a monoclonal antibody against the RANKL, was demon- strated to produce a tumor response in $86 \%$ of patients in an open-label Phase 2 study by Thomas et al. ${ }^{18}$ The patients in this study had atypical GCTs, which were unresectable, recurrent, or metastatic, the minority of which were located in the spine. Thomas suggested that further studies are required with denosumab, in particular to assess its potential therapeutic effects in reducing tumor size before surgery. To our knowledge the use of denosumab as an adjunct to surgery has not yet been described, nor has its effect been studied specifically in primary spine GCT.

The current study reports on a prospective series of patients with primary GCT of the spine. These patients either underwent resection of GCTs after neoadjuvant denosumab treatment or were treated with denosumab following surgical stabilization of GCT-induced spinal instability. The clinical, radiological, and histological tumor responses are described. To our knowledge, this is the first reported series of such patients with GCT in the spine.

\section{Methods \\ Study Population}

A prospective, consecutive series of patients with primary spinal GCTs that were treated with denosumab was included. The following centers were involved in this study: Vancouver General Hospital, Vancouver, BC, Canada, (2 patients); MD Anderson Cancer Center, Houston, Texas; James Cancer Center, Columbus, Ohio; and the Radcliffe Royal Infirmary, Oxford, UK. The institutional review board at each of these institutions approved the study.

TABLE 1. Demographic data and presentation in 5 patients with GCTs treated with denosumab

\begin{tabular}{|c|c|c|c|c|c|}
\hline Factor & Case 1 & Case 2 & Case 3 & Case 4 & Case 5 \\
\hline \multicolumn{6}{|l|}{ Demographic } \\
\hline Sex & $\mathrm{F}$ & $\mathrm{F}$ & $\mathrm{F}$ & $\mathrm{F}$ & $\mathrm{F}$ \\
\hline Age (yrs at diagnosis) & 33 & 32 & 58 & 46 & 22 \\
\hline Ethnicity & Hispanic & Caucasian & Caucasian & Caucasian & Caucasian \\
\hline \multicolumn{6}{|l|}{ Clinical } \\
\hline Initial presentation & Pain \& neurology & Pain \& neurology & Pain & Pain & $\begin{array}{l}\text { Pain \& pathological } \\
\text { fracture }\end{array}$ \\
\hline Duration of Sxs & 16 wks & $\begin{array}{l}12 \text { wks of neuro Sxs } \\
\text { (3 yrs of back pain) }\end{array}$ & 124 wks & 10 wks & 2 wks \\
\hline Neurology (ASIA score) & $\mathrm{D}$ & $\mathrm{D}$ & $E$ & $E$ & $E$ \\
\hline Neurology (other) & $\begin{array}{l}\text { Myelopathy \& } \\
\text { radiculopathy }\end{array}$ & Radiculopathy & None & None & None \\
\hline Other oncological history & None & None & None & None & None \\
\hline \multicolumn{6}{|l|}{ Tumor } \\
\hline Location & T5-7 & T12-L2 & S1-3 & T12-L1 & $\mathrm{C}-2$ \\
\hline Tumor size in $\mathrm{cm}^{*}$ & $4.5 \times 4.5 \times 4.8$ & $7.7 \times 7.5 \times 5.8$ & $6 \times 9 \times 5$ & $15 \times 15 \times 15$ & NA \\
\hline WBB sector & $4-11$ & $1-9+12$ & $6-10$ & $4-9$ & $5-8$ \\
\hline WBB layers & $A-D$ & A-D & $A-D$ & $A-C$ & $A-D$ \\
\hline Enneking class & Stage III & Stage III & Stage III & Stage III & Stage III \\
\hline
\end{tabular}

class = classification; $\mathrm{NA}=$ not applicable; neuro $=$ neurological; Sxs = symptoms .

* Length $\times$ width $\times$ height at largest points. 


\section{Baseline Characteristics}

The following data were collected at baseline: patient demographic data, duration of symptoms, mode of presentation, neurological status, oncological history, Enneking and Weinstein-Boriani-Biagini (WBB) grading, and radiological and biopsy characteristics of the tumor.

\section{Treatment Protocol}

The dose, duration, and side effects of denosumab treatment were recorded. Both clinical and radiological patient follow-up was documented. Operative details including procedure type, surgical margins, and perioperative and postoperative complication data were collected.

\section{Pathological and Clinical Outcomes}

The pathological analysis of the surgical specimen, including tumor viability and RANKL staining, if tumor cells were present, was collected. The latest clinical status of each patient from a local control and survival standpoint is reported.

\section{Results}

\section{Demographic Data and Presentation}

Five patients met the study criteria and were included. All patients had a histological diagnosis of GCT confirmed by CT-guided needle biopsy. All patients were women, with a mean age of $38.2 \pm 13.9$ years (range $22-58$ years). All patients presented with pain, and 2 patients had additional neurological signs and symptoms. These 2 patients were American Spinal Injury Association (ASIA) Impairment Scale Grade D, and the other 3 patients were ASIA Grade E. The mean duration of symptoms was 62

TABLE 2. Treatment and outcome in 5 patients with GCTs

\begin{tabular}{|c|c|c|c|c|c|}
\hline Treatment & Case 1 & Case 2 & Case 3 & Case 4 & Case 5 \\
\hline \multicolumn{6}{|l|}{ Denosumab } \\
\hline Duration (mos) & 5 & 6 & 6 & 7 & Ongoing \\
\hline $\begin{array}{l}\text { Drug-related adverse } \\
\text { events }\end{array}$ & None & None & None & None & None \\
\hline \multicolumn{6}{|l|}{ Other treatment } \\
\hline Embolization & Single & Single & Single & Multiple & None \\
\hline \multicolumn{6}{|l|}{ Surgery } \\
\hline Time from diagnosis (days) & 150 & 220 & 861 & 723 & Arthrodesis only \\
\hline $\begin{array}{l}\text { Time from denosumab } \\
\text { start (days) }\end{array}$ & 145 & 161 & 319 & 392 & $\begin{array}{l}\text { Denosumab com- } \\
\text { menced } 10 \text { mos } \\
\text { postfusion }\end{array}$ \\
\hline $\begin{array}{l}\text { Time from denosumab end } \\
\text { (days) }\end{array}$ & 41 & 14 & 139 & 127 & NA \\
\hline Planned op & Piecemeal & En bloc & Piecemeal & En bloc & Arthrodesis only \\
\hline $\begin{array}{l}\text { Margins perceived by } \\
\text { surgeon }\end{array}$ & Intralesional & Marginal & Intralesional & Marginal & NA \\
\hline Intraop complications & None & Dural tear & Dural tear $\times 2$ & $\begin{array}{l}\text { Dural tear } \times 2 \text {; signifi- } \\
\quad \text { cant blood loss }\end{array}$ & None \\
\hline Postop complications & None & CSF leak & $\begin{array}{l}\text { Lt S-1 weakness; } \\
\text { decreased anal } \\
\text { tone \& urinary } \\
\text { retention; UTI }\end{array}$ & $\begin{array}{l}\text { UTI; orthostatic } \\
\text { hypotension }\end{array}$ & None \\
\hline \multicolumn{6}{|l|}{ Radiology } \\
\hline $\begin{array}{l}\text { Tumor change after } \\
\text { denosumab treatment }\end{array}$ & $40 \%$ size reduction & $\begin{array}{l}\text { 10\% reduction } \\
\quad \text { (mainly w/in canal) }\end{array}$ & $\begin{array}{l}10 \% \text { reduction } \\
\text { after } 3 \text { rd cycle }\end{array}$ & $\begin{array}{l}10 \% \text { reduction after } \\
3 \text { rd cycle }\end{array}$ & $\begin{array}{l}\text { Near complete } \\
\text { regression after } \\
\text { 3rd cycle }\end{array}$ \\
\hline Calcification & Minimal & Yes & Yes & Yes & Yes \\
\hline \multicolumn{6}{|l|}{ Pathology } \\
\hline Pretreatment biopsy details & Hypercellular GCT & GCT & GCT & GCT & GCT \\
\hline Surgical specimen details & $\begin{array}{l}>90 \% \text { tumor cells } \\
\text { still viable, \& } \\
\text { diffuse RANKL } \\
\text { staining }\end{array}$ & $0 \%$ & $0 \%$ & $0 \%$ & NA \\
\hline Final pathology margins & Intralesional & Marginal & Intralesional & Marginal & NA \\
\hline Duration of follow-up (mos) & 4 & 26 & 5 & 5 & 24 \\
\hline
\end{tabular}

$\mathrm{UTI}=$ urinary tract infection. 
\pm 73.9 weeks (range $2-158$ weeks). No patient had a prior oncological history or metastatic disease at presentation. All patients had Enneking Stage III (aggressive) tumors, the size and location of which are shown in Table 1 along with a summary of the patients' demographic data.

\section{Tumor Histological Findings}

The tumors included in this case series were all conventional GCTs of bone consisting of sheets of numerous osteoclast-like multinucleated giant cells with plump eosinophilic cytoplasm and vesicular nuclei exhibiting prominent nucleoli, regularly dispersed among numerous mononuclear rounded or oval stromal cells. The mitotic count was variable and only typical mitotic figures were found.

\section{Denosumab Treatment}

All patients were treated with monthly cycles of 120 $\mathrm{mg}$ of denosumab with initial additional loading doses on Days 8 and 15. Patients were given daily supplements of calcium $(500 \mathrm{mg})$ and vitamin D (400 IU). Patients were closely monitored by the medical oncology service. Denosumab was discontinued preoperatively in all patients who underwent tumor resection. Patients had received denosumab for an average of 6 months (range 5-7 months) preoperatively. The patient in Case 5 did not undergo tumor resection; rather, arthrodesis alone. Denosumab treatment was offered but was commenced 10 months later because the patient sought other opinions. This patient remains on denosumab and was tolerating it well at the 24-month follow-up. No drug-related adverse events or complications were noted in any patient.

\section{Surgery and Perioperative Complications}

All patients who underwent tumor resection had preoperative angiographic arterial embolization. The method of tumor resection was either by piecemeal or en bloc resection as shown in Table 2. There was perfect correlation between the intraoperative tumor margins perceived by the surgeon and the margins confirmed by the pathologist. In cases in which the tumor margin was encountered the surgeon reported a firmer consistency of the tumor capsule, which aided in resection. Three patients had intraoperative durotomies, and in 1 patient there was an ongoing postoperative CSF leak that required operative repair. One patient sustained sacral nerve injuries resulting in left plantar flexion weakness and bowel and bladder dysfunction that subsequently resolved. One patient had significant intraoperative blood loss and postoperative orthostatic hypotension that resolved. Two patients experienced urinary tract infections.

\section{Tumor Response to Denosumab}

Imaging revealed a reduction in tumor size in all patients. This reduction was $10 \%$ in the patients in Cases $2-4$ and $40 \%$ in the patient in Case 1. The reduction in size tended to be more in the epidural region of the tumor (see Figs. 1-5). In the patient in Case 5, who did not undergo tumor resection, a near complete resolution (>90\%) of tumor was noted, with remodeling of the C-2 vertebra.
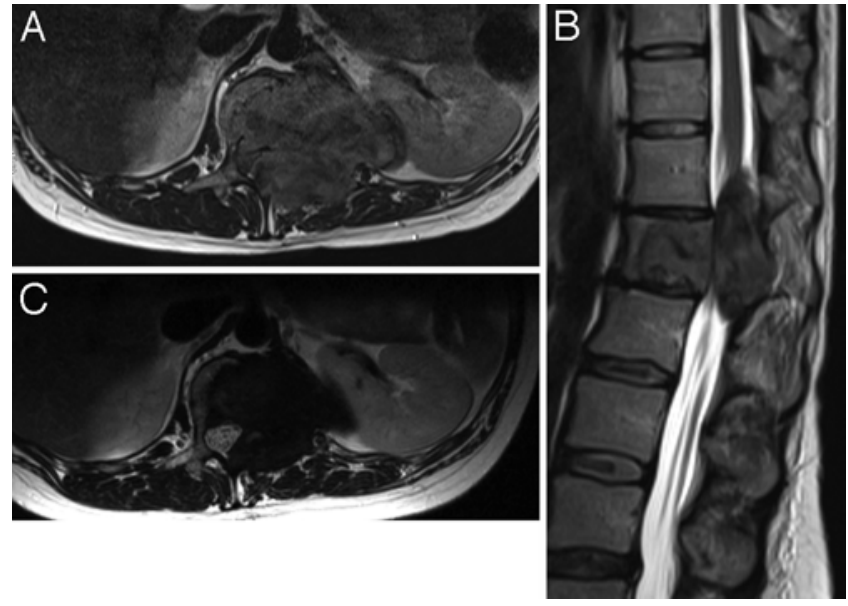

FIG. 1. Preoperative axial (A) and sagittal (B) MRI studies showing tumor completely effacing the thecal sac. Axial MRI study (C) after 3 cycles of denosumab treatment showing shrinkage of the tumor, particularly around the thecal sac, which is now visible.

In 3 patients who underwent imaging after the third cycle of denosumab treatment, this reduction was noted at this time point, with no further size reduction on subsequent imaging between 3 and 7 months later.

Final histological investigation revealed complete obliteration of all tumor cells and replacement with sclerotic fibro-osseous tissue with interstitial hemosiderin in 3 of 4 patients. In the patient in Case 1,>90\% viable tumor cells were present on final histological investigation and there was diffuse RANKL staining on immunhistochemical analysis. The initial pathology study in this patient showed a hypercellular GCT, but there were no other features that could account for her lack of response. No repeat biopsy was performed in the patient in Case 5.

\section{Postoperative Outcome}

The mean follow-up duration was 12 months (range 4.5-26 months). All patients are alive with no evidence of local recurrence clinically or on follow-up imaging. The patient in Case 5 remains on denosumab and has had no drug-related complications to date.

\section{Discussion}

In a recent international, open-label, Phase 2 trial of patients with histologically confirmed GCT of the bones and radiographically measurable active disease, denosumab has demonstrated a very safe profile as well as a very high response rates. ${ }^{8,18}$ To our knowledge, this is the first study in which patients with primary spinal GCT were treated with denosumab. In 4 patients, denosumab was used as an adjunct to surgery. In the fifth patient it was used as a stand-alone treatment because the surgery performed was for stabilization only, with no attempt at tumor resection due to the complex anatomical location and extent of tumor. Interestingly, this patient had the best radiological response, with near complete tumor regression. It is unclear why this occurred; however, it is possible that the altered segmental biomechanics and loading character- 

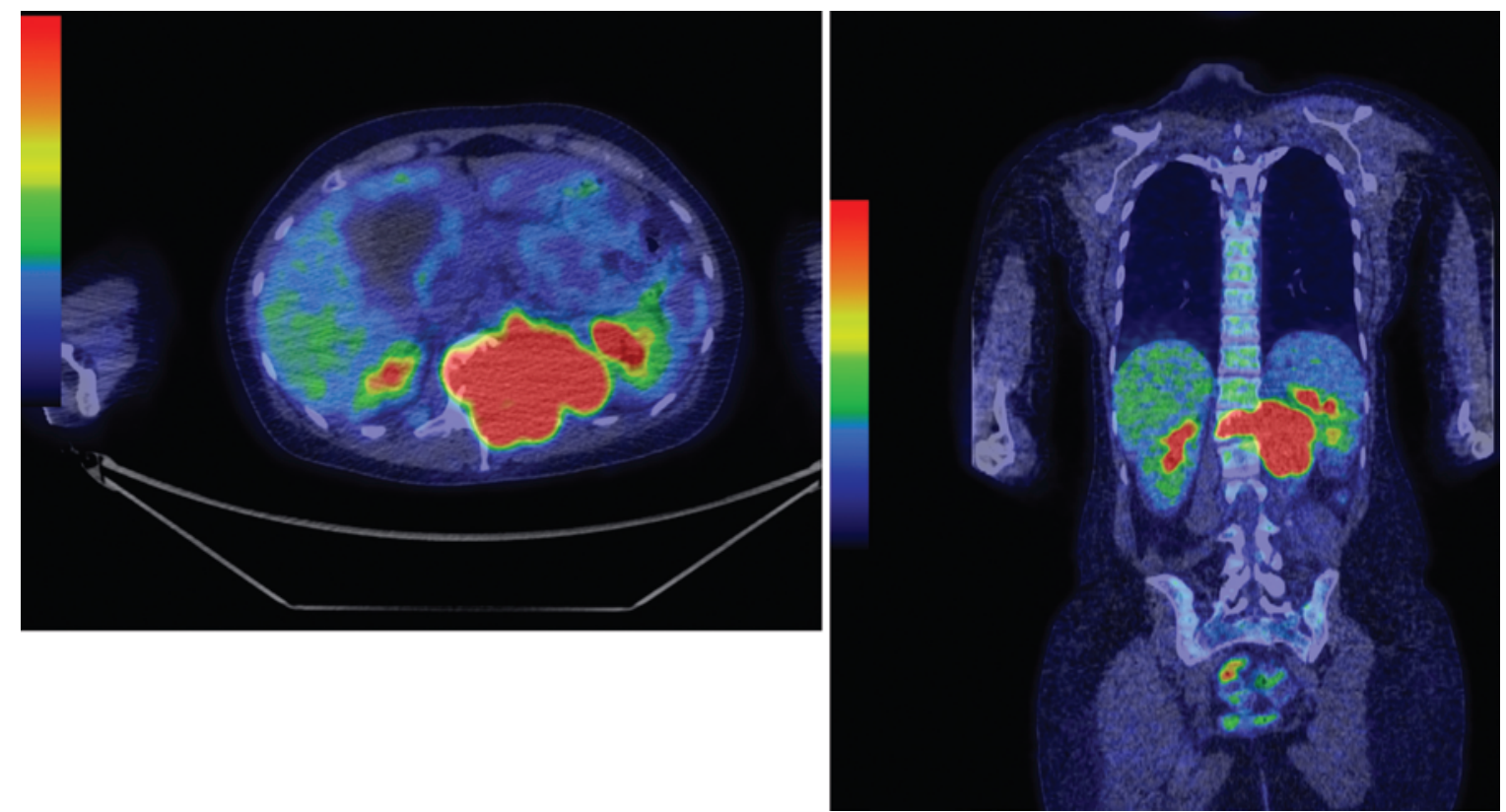

FIG. 2. Axial (left) and coronal (right) FDG-PET CT scan at baseline showing metabolically active tumor. Figure is available in color online only.

istics of the tumor cells following surgical stabilization may have played a role. It is important to note that in this patient no repeat biopsy was performed, and the histological response to denosumab is therefore unknown. This patient remains on denosumab and has remained stable on follow-up, both from a symptomatic and a radiological standpoint.

The radiological response seen in the patients in this study was similar to that described by Thomas et al. ${ }^{18}$ as stable with some slight regression. In our study all tumors decreased in size by at least $10 \%$, with the exception of the patient in Case 5, who had a near complete radiological response, as previously described. In 3 patients who underwent imaging after the third cycle, the reduction in size was apparent at this time point, and in subsequent imaging no additional major difference was seen. The other 2 patients underwent repeat imaging only after completion of denosumab treatment, at which point the size reduction was noted. Thomas et al. also described the presence of tumor calcification seen on imaging following denosumab treatment. This was a consistent finding in the patients in this study; however, there was only minimal calcification
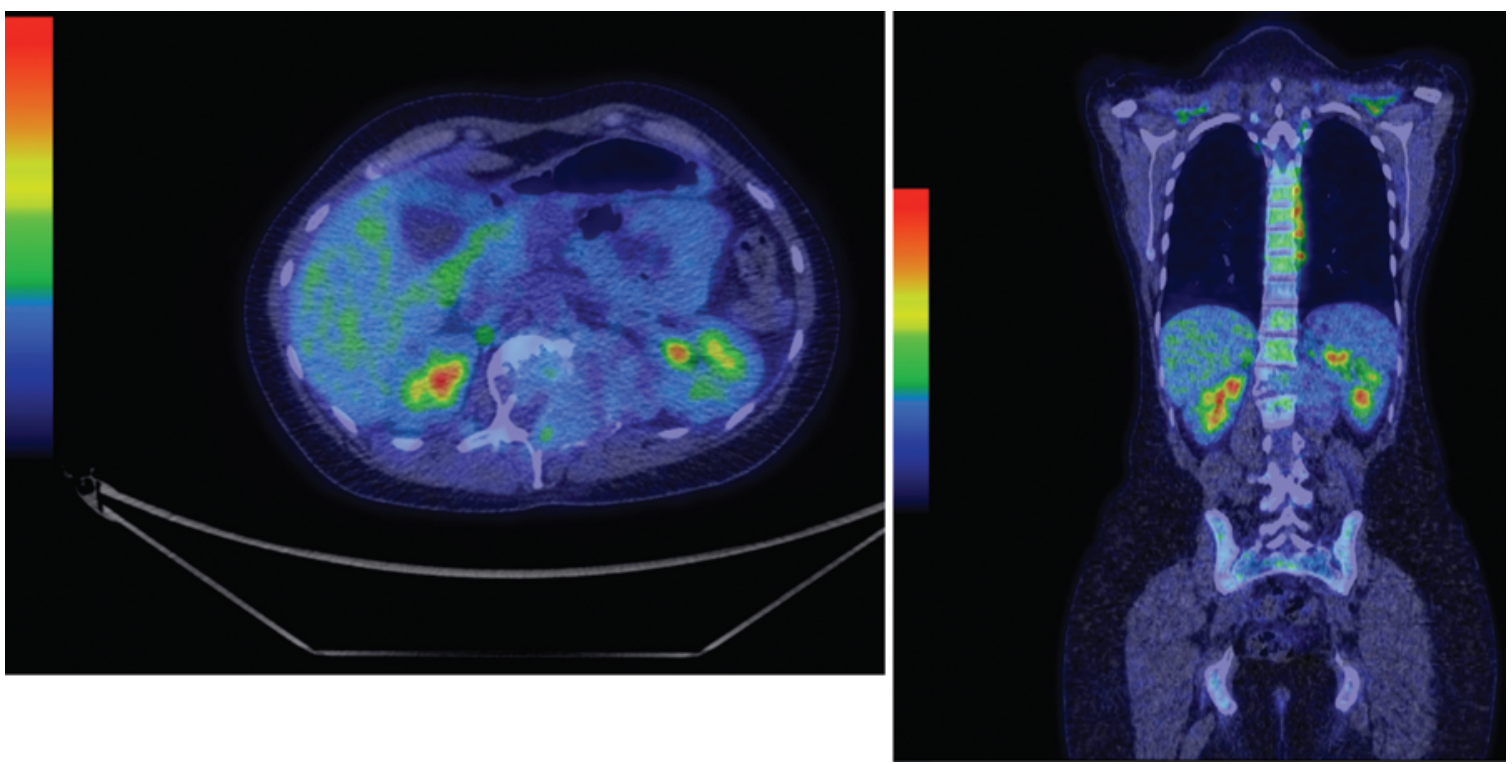

FIG. 3. Axial (left) and coronal (right) FDG-PET CT scan obtained after 3 cycles of denosumab showing no FDG uptake by the tumor, with no metabolically active disease present. Figure is available in color online only. 

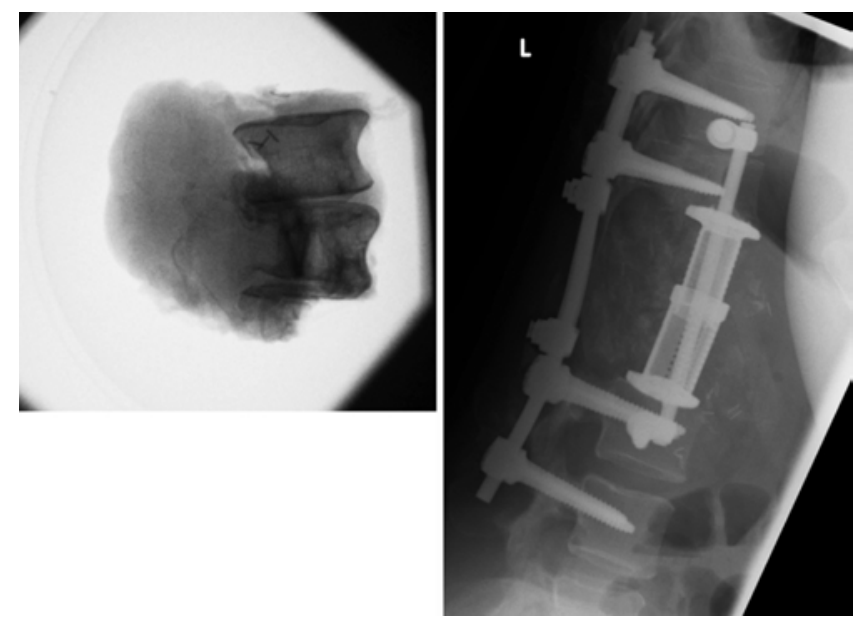

FIG. 4. Surgical specimen (left) after en bloc resection and lateral postoperative radiograph (right) showing reconstruction.

in the patient in Case 1, and it was in this patient that only a minimal histological response to denosumab was noted, as will subsequently be discussed. The size reduction and calcification are both features that are immensely helpful to the spine surgeon. Shrinkage can reduce the size of resection, helping preserve critical anatomy. Calcification or increasing the firmness of the tumor capsule facilitates surgical orientation and theoretically reduces the risk of tumor margin violation.

There was a complete histological response in 3 of 4 patients, with no evidence of viable tumor cells in the surgical specimen. In the fourth patient (Case 1) there was significant evidence of viable tumor cells, with $>90 \%$ still present. These cells exhibited diffuse RANKL staining on immunohistochemical analysis. This patient was noted to have a hypercellular GCT on the initial biopsy, but there was no apparent reason for her lack of response. This patient was treated for 5 months with denosumab preoper- atively and imaging revealed a $40 \%$ reduction in tumor size; however, CT scans exhibited only minor calcification. There were no such histological failures in Thomas et al.'s study, in which a histological response was defined as > $90 \%$ elimination of tumor cells. However, not all of the patients in that study had histological analysis of their lesion. There were 2 patients who withdrew from the study due to tumor progression, and the overall response rate was $86 \%$ based on either histological or radiological criteria. The histological failure in this study was a radiological success from a tumor shrinkage perspective. This emphasizes the need for histological analysis of tumor response.

There are 3 important observations worthy of mention. First, there appeared to be a different response seen on imaging of the tumor within the vertebrae compared with surrounding or extracompartmental tumor. Following denosumab treatment there was remodeling of the vertebrae, whereas extracompartmental GCT tended to shrink only slightly and calcify. This may be due to the constituent environment within the vertebrae that contains native osteoblasts, osteoclasts, and stromal cells that may exhibit different cell signaling with the tumor cells as compared with extracompartmental GCT lacking these constituent cells. The inhibition of RANKL by denosumab has been reported to act via reciprocal signaling between stromal and neoplastic cells. ${ }^{18,19}$ Following the death of tumor cells, osteoid and bone replacement can occur within a previously affected vertebra. It is also possible that the ability of the vertebrae to bear a load accounts for at least part of the difference in response to the extracompartmental component of the GCT.

The second observation is that epidural GCT had greater regression following denosumab treatment, and this may be due to the pulsatility of the dura mater, which probably inhibits new bone formation. Third, as mentioned above, the postoperative viable histological failure in our series exhibited the least amount of calcification on followup imaging. Calcification is a manifestation of new bone formation, which was noted by Thomas and colleagues to
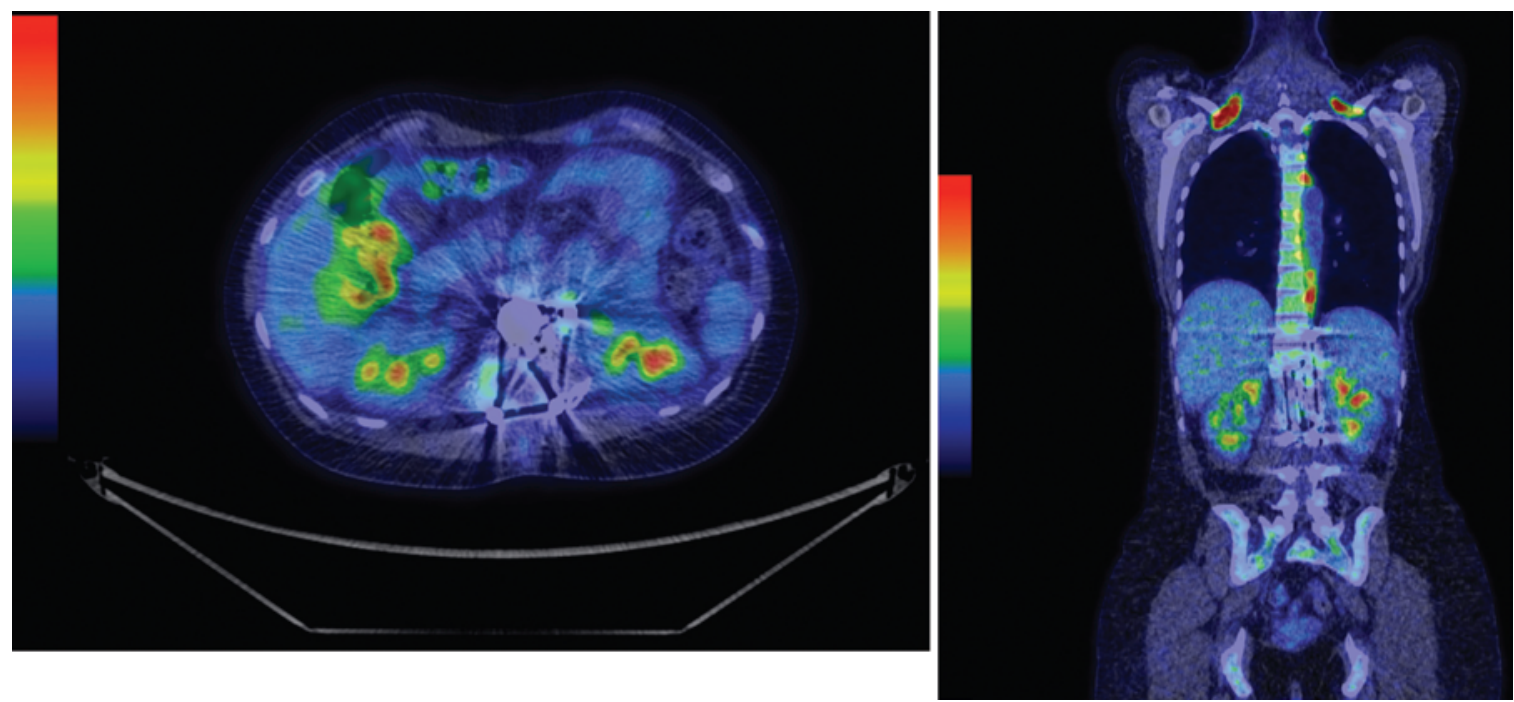

FIG. 5. Axial (left) and coronal (right) FDG-PET CT scan obtained 6 months postoperatively demonstrating no FDG uptake, suggesting no recurrence; note artifact from spinal implants. Figure is available in color online only. 
occur in conjunction with a decrease in FDG-PET activity. Although firm conclusions cannot be made from these observations in a small prospective case series, it would be useful to study these effects in larger cohorts.

There is no evidence, either clinically or radiologically, of tumor recurrence in any patient in this study. All patients were alive and well at last follow-up. It is probable that in the patients who have had both a complete histological response and tumor resection an oncological cure has been achieved; however, follow-up is not nearly long enough to make any firm conclusions.

Giant cell tumors of the spine provide unique challenges due to their proximity to neurovascular structures and the need for complex reconstructions following resection. En bloc resection with wide margins is the recommended surgical treatment for Enneking Stage III tumors. ${ }^{2,5,7,9}$ There is significant morbidity associated with this surgery evident in both the current and previous series. ${ }^{2}$ In this study, denosumab was given preoperatively with the aim of shrinking and calcifying the tumor, thereby improving the ease and safety of surgery. In addition to this benefit, the surgeons reported a firmer pseudocapsule on the marginal surface of tumor, improving the surgical plane and ease of resection. One key question that must be asked, however, is whether surgery is in fact necessary following denosumab treatment. Would a repeat biopsy after denosumab treatment followed by close surveillance in asymptomatic patients be an appropriate management strategy? Clearly, in 1 patient with a large number of viable cells after denosumab treatment, this may not be the case. In patients with a surgical indication such as neural compression or spinal instability, perhaps a less invasive surgical procedure could be performed due to a change in oncological goals with viable medical treatment.

The spinal GCTs in this series treated with denosumab constitute the first such reported cases. The limitations of this study are that it contains a low number of patients, limited follow-up, and no cohort. There was also a wide variation in time between presentation and surgery. This was due to many factors, including observation while receiving denosumab for varying periods of time because there is no standard established. Although a prospective cohort would be valuable, a retrospective or historical cohort would be difficult because of the outcomes we studied. Longer-term outcomes such as local recurrence and survival can be evaluated prospectively or with retrospective cohorts when more patients and longer follow-up is available. Despite these limitations it is extremely important to get out into the literature the favorable impact of denosumab on surgical treatment, because the impact on treatment and patient outcome is striking.

Although conclusions about denosumab as a neoadjuvant therapy to surgery or as an alternative to surgery cannot be made from this small series alone, we believe that the dramatic responses seen in this very first series of patients warrants dissemination. Spine surgeons and oncologists who are faced with patients with spinal GCT will need to provide an individualized approach based on tumor characteristics and patient factors. As the denosumab experience increases, answers to the above questions will become clearer. Denosumab will hopefully prove to be an important agent in the treatment of spinal GCT by reducing surgical risk and functional impairment, perhaps obviating the need for surgery at all in select patients.

\section{Conclusions}

This study reports the early experience of using denosumab in the treatment of spinal GCT. The results demonstrate a clinically beneficial radiological response and an impressive histological response in most but not all patients. Further experience with denosumab and longer patient follow-up is required. Denosumab has the potential to change the treatment paradigm for spinal GCT.

\section{Acknowledgments}

We thank Professor Nielson for his assistance with the pathological aspects of this study. We would also like to thank Dr. Kevin Bradley, Consultant in Radiology and Nuclear Imaging (PET), Oxford University Hospitals NHS Trust, for providing and interpreting images.

\section{References}

1. Arpornchayanon O, Leerapun T: Effectiveness of intravenous bisphosphonate in treatment of giant cell tumor: a case report and review of the literature. J Med Assoc Thai 91:16091612,2008

2. Boriani S, Bandiera S, Casadei R, Boriani L, Donthineni R, Gasbarrini A, et al: Giant cell tumor of the mobile spine: a review of 49 cases. Spine (Phila Pa 1976) 37:E37-E45, 2012

3. Boriani S, Bandiera S, Donthineni R, Amendola L, Cappuccio M, De Iure F, et al: Morbidity of en bloc resections in the spine. Eur Spine J 19:231-241, 2010

4. Boriani S, Saravanja D, Yamada Y, Varga PP, Biagini R, Fisher CG: Challenges of local recurrence and cure in low grade malignant tumors of the spine. Spine (Phila Pa 1976) 34 (22 Suppl):S48-S57, 2009

5. Boriani S, Weinstein JN, Biagini R: Primary bone tumors of the spine. Terminology and surgical staging. Spine (Phila Pa 1976) 22:1036-1044, 1997

6. Caudell JJ, Ballo MT, Zagars GK, Lewis VO, Weber KL, Lin $\mathrm{PP}$, et al: Radiotherapy in the management of giant cell tumor of bone. Int J Radiat Oncol Biol Phys 57:158-165, 2003

7. Chan P, Boriani S, Fourney DR, Biagini R, Dekutoski MB, Fehlings MG, et al: An assessment of the reliability of the Enneking and Weinstein-Boriani-Biagini classifications for staging of primary spinal tumors by the Spine Oncology Study Group. Spine (Phila Pa 1976) 34:384-391, 2009

8. Chawla S, Henshaw R, Seeger L, Choy E, Blay JY, Ferrari $S$, et al: Safety and efficacy of denosumab for adults and skeletally mature adolescents with giant cell tumour of bone: interim analysis of an open-label, parallel-group, phase 2 study. Lancet Oncol 14:901-908, 2013

9. Fisher CG, Saravanja DD, Dvorak MF, Rampersaud YR, Clarkson PW, Hurlbert J, et al: Surgical management of primary bone tumors of the spine: validation of an approach to enhance cure and reduce local recurrence. Spine (Phila Pa 1976) 36:830-836, 2011

10. Gille O, de Azevedo Oliveira B, Guerin P, Lepreux S, Richez C, Vital JM: Regression of giant cell tumor of the cervical spine with bisphosphonate as single therapy. Spine (Phila Pa 1976) 37:E396-E399, 2012

11. Harrop JS, Schmidt MH, Boriani S, Shaffrey CI: Aggressive "benign" primary spine neoplasms: osteoblastoma, aneurysmal bone cyst, and giant cell tumor. Spine (Phila Pa 1976) 34 (22 Suppl):S39-S47, 2009

12. Junming M, Cheng Y, Dong C, Jianru X, Xinghai Y, Quan H, 
et al: Giant cell tumor of the cervical spine: a series of 22 cases and outcomes. Spine (Phila Pa 1976) 33:280-288, 2008

13. Refai D, Dunn GP, Santiago P: Giant cell tumor of the thoracic spine: case report and review of the literature. Surg Neurol 71:228-233, 2009

14. Roeder F, Timke C, Zwicker F, Thieke C, Bischof M, Debus $\mathrm{J}$, et al: Intensity modulated radiotherapy (IMRT) in benign giant cell tumors - a single institution case series and a short review of the literature. Radiat Oncol 5:18, 2010

15. Samartzis D, Foster WC, Padgett D, Shen FH: Giant cell tumor of the lumbar spine: operative management via spondylectomy and short-segment, 3-column reconstruction with pedicle recreation. Surg Neurol 69:138-142, 2008

16. Sansur CA, Pouratian N, Dumont AS, Schiff D, Shaffrey CI, Shaffrey ME: Spinal cord neoplasms - primary tumours of the bony spine and adjacent soft tissues. Lancet Oncol 8:137-147, 2007

17. Sundaresan N, Boriani S, Okuno S: State of the art management in spine oncology: a worldwide perspective on its evolution, current state, and future. Spine (Phila Pa 1976) 34 (22 Suppl):S7-S20, 2009

18. Thomas D, Henshaw R, Skubitz K, Chawla S, Staddon A, Blay JY, et al: Denosumab in patients with giant-cell tumour of bone: an open-label, phase 2 study. Lancet Oncol 11:275280,2010

19. Thomas DM, Skubitz KM: Giant cell tumour of bone. Curr Opin Oncol 21:338-344, 2009

20. Tse LF, Wong KC, Kumta SM, Huang L, Chow TC, Griffith JF: Bisphosphonates reduce local recurrence in extremity giant cell tumor of bone: a case-control study. Bone 42:68-73, 2008

21. Xu W, Li X, Huang W, Wang Y, Han S, Chen S, et al: Factors affecting prognosis of patients with giant cell tumors of the mobile spine: retrospective analysis of 102 patients in a single center. Ann Surg Oncol 20:804-810, 2013

\section{Author Contributions}

Conception and design: Fisher, Goldschlager. Acquisition of data: Goldschlager, Dea, Boyd, Reynolds, Patel, Rhines, Mendel, Ramos. Analysis and interpretation of data: Goldschlager, Dea, Reynolds, Patel, Pacheco. Drafting the article: Goldschlager, Patel, Pacheco, Mattei. Critically revising the article: all authors. Reviewed submitted version of manuscript: all authors. Approved the final version of the manuscript on behalf of all authors:

Fisher. Statistical analysis: Goldschlager. Study supervision: Fisher.

\section{Supplemental Information}

\section{Current Affiliation}

Dr. Dea: Division of Neurosurgery, Department of Surgery, Université de Sherbrooke, Quebec, Canada.

\section{Abstract Submission}

Cases 2 and 5 have been submitted as case report abstracts.

\section{Correspondence}

Charles G. Fisher, Division of Spine Surgery, University of British Columbia and Vancouver General Hospital, Blusson Spinal Cord Centre, 818 W. 10th Ave., Vancouver, BC V5Z 1M9, Canada. email: charles.fisher@vch.ca. 